\title{
Association Between Body-Mass Index and Quality of Split Bowel Preparation
}

\author{
Nabil F. Fayad ${ }^{1,2}$, Charles J. Kahi ${ }^{1,2}$, Khaled H. Abd el-jawad ${ }^{1}$, Andrea S. Shin ${ }^{1}$, Shenil \\ Shah $^{1}$, Kathleen A. Lane ${ }^{3}$, and Thomas F. Imperiale ${ }^{1,4,5}$ \\ ${ }^{1}$ Division of Gastroenterology and Hepatology, Department of Medicine, Indiana University \\ School of Medicine, Indianapolis, Indiana \\ 2Section of Gastroenterology and Hepatology, Medicine Department, Richard L. Roudebush VA \\ Medical Center, Indianapolis, Indiana \\ ${ }^{3}$ Department of Biostatistics, Indiana University School of Medicine, Indianapolis, Indiana \\ ${ }^{4}$ Center of Excellence for Implementing Evidence-based Research, Richard L. Roudebush VA \\ Medical Center, Indianapolis, Indiana \\ ${ }^{5}$ Regenstrief Institute, Inc., Indianapolis, Indiana
}

\begin{abstract}
Background and Aims-Little is known about the association between obesity and bowel preparation. We investigated whether body-mass index (BMI) is an independent risk factor for inadequate bowel preparation in patients who receive split preparation regimens.
\end{abstract}

Methods-We performed a retrospective study of data from 2163 consecutive patients (mean age, $60.6 \pm 10.5$ y; $93.8 \%$ male) who received outpatient colonoscopies in 2009 at the Veterans Affairs Medical Center in Indianapolis, Indiana. All received a split preparation, categorized as adequate (excellent or good, based on the Aronchick scale) or inadequate. We performed multivariable analysis to identify factors independently associated with inadequate preparation.

Results-Bowel preparation quality was inadequate for $44.2 \%$ of patients; these patients had significantly higher mean BMIs than patients with adequate preparation ( $31.2 \pm 6.5$ vs $29.8 \pm 5.9$, respectively; $P<.0001)$ and Charlson comorbidity scores $(1.5 \pm 1.6$ vs $1.1 \pm 1.4 ; P<.0001)$. Independent risk factors for inadequate preparation were BMI $\geq 30 \mathrm{~kg} / \mathrm{m}^{2}$ (odds ratio [OR], 1.46; 95\% confidence interval [CI], 1.21-1.75; $P<.0001$ ), use of tobacco (OR, 1.28; 95\% CI, 1.07-1.54; $P=.0084$ ) or narcotics (OR, 1.28; 95\% CI, 1.04-1.57; $P=.0179)$, hypertension (OR, 1.30; 95\% CI,

\footnotetext{
(C) 2013 The American Gastroenterological Association. Published by Elsevier Inc. All rights reserved.

Corresponding Author: Nabil F. Fayad, M.D., Assistant Professor of Clinical Medicine, Division of Gastroenterology and Hepatology, Department of Medicine, Indiana University School of Medicine \& Richard L. Roudebush VA Medical Center, 1481 W. 10 th St., Room 111G, Indianapolis, Indiana 46202, nfayad@iu.edu, Telephone: 317-988-3120, Fax: 317-988-3243.

Author Contributions:

N. Fayad, C. Kahi and T. Imperiale were involved in study concept and design; funding acquisition; acquisition, analysis and interpretation of data; and writing of the manuscript. K. Abd el-jawad, A. Shin and S. Shah were involved in acquisition, analysis and interpretation of data. K. Lane was involved in statistical analysis and interpretation of data.

Disclosures:

All the authors disclose no conflicts of interest.

Publisher's Disclaimer: This is a PDF file of an unedited manuscript that has been accepted for publication. As a service to our customers we are providing this early version of the manuscript. The manuscript will undergo copyediting, typesetting, and review of the resulting proof before it is published in its final citable form. Please note that during the production process errors may be discovered which could affect the content, and all legal disclaimers that apply to the journal pertain.
} 
$1.07-1.57 ; P=.0085)$, diabetes (OR, 1.38; 95\% CI, 1.12-1.69; $P=.0021)$, and dementia (OR, 3.02; 95\% CI, 1.22-7.49; $P=.0169)$.

Conclusions-BMI is an independent factor associated with inadequate split bowel preparation for colonoscopy. Additional factors associated with quality of bowel preparation include diabetes, hypertension, dementia, and use of tobacco and narcotics. Patients with BMIs $\geq 30 \mathrm{~kg} / \mathrm{m}^{2}$ should be considered for more intensive preparation regimens.

\section{Keywords}

Colonoscopy preparation; colorectal cancer screening; overweight; adenoma detection

\section{Introduction}

Colonoscopy is a powerful tool for colorectal cancer (CRC) prevention, as it allows the detection and removal of precursor adenomatous polyps. The effectiveness of colonoscopy depends on several factors, foremost of which is the adequacy of visualization of the colonic mucosa, allowing a thorough inspection for colon neoplasms. Studies have shown that a poor bowel preparation is associated with lower adenoma detection rates $(1,2)$.

Despite the importance of preparation quality, there is no widely accepted definition of the precise characteristics of an adequate bowel preparation. The U.S. Multi-Society Task Force on Colorectal Cancer, and the ASGE/ACG Taskforce on Quality in Endoscopy state that an adequate preparation is one in which polyps $>5 \mathrm{~mm}$ can be reliably visualized (3, 4). A 2010 meta-analysis showed that about $25 \%$ of patients do not achieve adequate preparation quality with polyethylene glycol-based bowel preparations (5). Tailored preparation regimens would certainly be beneficial in these patients, if they could be identified prior to their procedure.

Obesity is one risk factor among several that is associated with unsatisfactory bowel preparation (6), although whether this applies to split dose regimens is uncertain. Split dose preparations, where a portion of the preparation is given on the day of the examination, are essential for adequate preparation quality and have become the standard in clinical practice (7-9). Split-dose preparations increase the proportion of adequate preparation quality, increase patient compliance, and improve patient tolerance (10). Other variables associated with inadequate bowel preparation are male gender, older age, constipation, diabetes, dementia, history of stroke, liver cirrhosis, use of tricyclic agents and unfavorable socioeconomic conditions (11-15). However, it is also not clear if these risk factors are pertinent to split-dose preparations.

Our aim was to determine whether body-mass index (BMI) is an independent risk factor for inadequate preparation in patients who receive a split preparation regimen.

\section{Materials and Methods}

\section{Population Description}

This retrospective cross-sectional study was conducted at the Richard L. Roudebush Veterans Affairs Medical Center (VAMC) in Indianapolis, Indiana, a tertiary care academic VAMC affiliated with Indiana University. Consecutive patients who underwent colonoscopy between 1/1/2009 and 12/31/2009 were considered for inclusion. The study was approved by the Indiana University Institutional Review Board and the Roudebush VAMC Research and Development Board. Patients were identified by querying the VA computerized patient record system (CPRS). Subjects were eligible for inclusion if they underwent elective outpatient colonoscopy during the study period. In the event that a patient underwent more 
than one colonoscopy, the first procedure only was included. Exclusion criteria consisted of patients with a prior colon resection; colonoscopies that were repeated within the study period due to prior poor bowel preparation; colonoscopies performed emergently, in hospitalized patients, after a two-day bowel preparation, or in underweight patients (BMI < $18.5 \mathrm{mg} / \mathrm{m}^{2}$, as these patients may be more likely to have underlying physical or psychological comorbidities that could preclude successful completion of the preparation and introduce unknown confounders to the analysis); and incomplete colonoscopies for reasons other than inadequate preparation (cecum not reached due to factors not related to bowel preparation).

\section{Bowel Preparation Description}

All patients received a polyethylene glycol-based split bowel preparation. The standard bowel preparation was a split 4 liters of Colyte ${ }^{\circledR}$ (Alaven Pharmaceutical, Marietta, GA); 2 to 3 liters were consumed the evening prior to the procedure (along with $20 \mathrm{mg}$ of Bisacodyl), and the remaining 1 to 2 liters were taken 4 hours prior to the colonoscopy. Two alternative split preparations were also used: MoviPrep ${ }^{\circledR}$ (Salix Pharmaceuticals, Raleigh, $\mathrm{NC}$ ), with 1 liter consumed the evening prior to the exam, and the second liter 4 hours ahead of the colonoscopy; or MiraLax ${ }^{\circledR}$ (Merck, Whitehouse Station, NJ), with $119 \mathrm{~g}$ consumed the evening before the test (along with $10 \mathrm{mg}$ of Bisacodyl) and another $119 \mathrm{~g}$ taken 4 hours before undergoing the colonoscopy.

\section{Data Collection}

The VA CPRS electronic medical records include demographic and clinical information. Our colonoscopy reports are generated using the Provation ${ }^{\circledR}$ system (Minneapolis, MN) and recorded in CPRS. Patient data collected included: demographic variables- age, gender, race, ethnicity, weight, height and BMI; comorbidities- coronary artery disease, congestive heart failure, diabetes mellitus, hypertension, stroke, dementia, liver cirrhosis, comorbidity count, and comorbidity burden using the Charlson comorbidity score (16); pertinent medication use- narcotics, calcium channel blockers, iron supplements, anticonvulsants and medications with anticholinergic properties (antispasmodics, antipsychotics, tricyclic agents and antiparkinsonian drugs); tobacco and alcohol use (excessive alcohol use was based on history of alcoholism, recurrent binge drinking or consuming regularly more than 2 drinks per day); and type of bowel preparation used. Colonoscopy data collected included: procedure indication, family history of colon cancer, bowel preparation type and quality, and findings. Preparation quality is subjectively assessed at our institution by each individual endoscopist according to the Aronchick scale: excellent, good, fair, poor and unsatisfactory (17). Colonoscopy findings recorded included presence of polyps, number, size, location and histology. The recommended follow-up colonoscopy interval was recorded, including whether the interval was shortened due to the preparation quality.

\section{Statistical Analysis}

Subjects were categorized based upon their colonoscopy preparation quality into two groups: adequate preparation (excellent or good preparation on the Aronchick scale) or inadequate preparation (fair, poor or unsatisfactory preparation). T-tests and Fisher's exact tests were used to compare both groups. BMI was categorized as normal (18.5 to $24.9 \mathrm{~kg} /$ $\mathrm{m}^{2}$ ); overweight (BMI between 25 and $30 \mathrm{~kg} / \mathrm{m}^{2}$ ) or obese (BMI over $30 \mathrm{~kg} / \mathrm{m}^{2}$ ). Logistic regression was used to model the association of BMI with inadequate preparation quality, which was done treating BMI both as a continuous and a categorical variable. From each model, Receiver Operator Characteristics (ROC) curves were generated and area under the curve (AUC) was measured to help determine an optimal BMI cutoff. Multivariable logistic regression analysis was performed to determine factors independently associated with inadequate preparation quality, with candidate variables having univariate $\mathrm{p}$-values $<0.20$. 
Multivariable logistic regression was also used to obtain and compare estimates of the adenoma detection rate for adequate and inadequate preparation quality, after adjusting for the terms in the final model on inadequate preparation quality.

\section{Results}

During the study period, 3124 subjects underwent colonoscopy, of which $700(22.4 \%)$ were excluded due to the following reasons: hospitalized status or emergent procedure $(n=256$; $36.6 \%$ ), incomplete colonoscopy (unrelated to preparation) $(\mathrm{n}=21 ; 3.0 \%)$, repeat colonoscopy due to poor preparation earlier in $2009(\mathrm{n}=71 ; 10.1 \%)$, colonoscopy following a 2-day preparation $(\mathrm{n}=155 ; 22.1 \%)$, subjects not undergoing a split preparation $(\mathrm{n}=8$; $1.1 \%)$, prior colon resection $(\mathrm{n}=168 ; 24.0 \%)$, and underweight $\left(\mathrm{BMI}<18.5 \mathrm{~kg} / \mathrm{m}^{2}\right)(\mathrm{n}=21$; $3.0 \%$ ). An additional 261 were excluded due to preparation quality not documented in the colonoscopy report $(\mathrm{n}=41)$, unavailable BMI data $(\mathrm{n}=209)$, and incomplete medical records $(n=11)$. Overall, 2163 subjects were included in the analysis. All colonoscopies were performed by one of seven staff endoscopists.

\section{Basic Characteristics}

Mean age of subjects in the study cohort was $60.6 \pm 10.5$ years; $93.8 \%$ were male; $82.5 \%$ were Caucasian. The mean Charlson score was $1.3 \pm 1.5$. Three hundred eighty-one patients (17.6\%) had a normal BMI; 774 (35.8\%) were overweight and $1008(46.6 \%)$ were obese. Colonoscopy was performed for colorectal cancer screening in 746 patients (34.6\%) and surveillance in 737 patients (34.1\%); the remainder 675 cases (31.3\%) were diagnostic colonoscopies, including 22 procedures performed to evaluate constipation (1.0\%). Most patients received a split Colyte ${ }^{\circledR}$ preparation $(\mathrm{n}=1953 ; 91.1 \%) ; 45$ subjects $(2.1 \%)$ received MoviPrep® and 146 subjects (6.8\%) received MiraLax ${ }^{\circledR}$ preparation.

Preparation quality was characterized as excellent in 26 subjects (1.2\%), good in 1181 (54.6\%), fair in $680(31.4 \%)$, poor in 246 (11.4\%), and unsatisfactory in 30 subjects (1.4\%). When the preparation variable was dichotomized, there were 1207 subjects $(55.8 \%)$ with adequate preparation quality and $956(44.2 \%)$ with inadequate preparation quality. There was no statistically significant difference between the two groups for gender, race, ethnicity, family history of colorectal cancer, or bowel preparation type. There were minor differences between both groups for age, tobacco and alcohol use. The proportion of patients who were undergoing colonoscopy for diagnostic indications, was slightly higher in the inadequate preparation quality group (Table 1).

\section{Univariate Analysis}

Mean BMI in the group of patients with inadequate bowel preparation quality was significantly higher than in the adequate preparation quality group: $31.2 \pm 6.5 \mathrm{~kg} / \mathrm{m}^{2}$ versus $29.8 \pm 5.9 \mathrm{~kg} / \mathrm{m}^{2}(\mathrm{p}<0.0001)$ (Table 1). Among subjects with inadequate bowel preparation quality, $53.0 \%$ were obese as compared with $41.5 \%$ of those with adequate preparation quality ( $\mathrm{p}<0.0001)$. Subjects with inadequate bowel preparation quality also had significantly more comorbidities and a higher mean Charlson score compared to those with adequate preparation quality. When specific comorbidities were assessed, those with inadequate preparation quality had higher rates of coronary artery disease, congestive heart failure, diabetes, hypertension, and dementia. In addition, more subjects with inadequate preparation quality were using narcotics or calcium channel blockers (Table 2).

Univariate logistic regression found that obese patients had a significantly higher risk for inadequate preparation quality compared to both overweight subjects and normal BMI (Table 3). Similarly, BMI treated as a continuous variable was significantly associated with 
inadequate preparation quality. Using a BMI cutoff point of $30 \mathrm{~kg} / \mathrm{m}^{2}$ maximizes the AUC at 0.558 (OR: $1.59 ; 95 \% \mathrm{CI}: 1.34-1.89 ; \mathrm{p}<0.0001)$.

\section{Multivariate Results}

Multivariable logistic regression analysis found that a BMI of $\geq 30 \mathrm{~kg} / \mathrm{m}^{2}$ was an independent risk factor for inadequate bowel preparation quality (OR: 1.46; 95\% CI: 1.21-1.75; $\mathrm{p}<0.0001$ ). In addition to BMI, hypertension, diabetes, dementia, tobacco use, and narcotics, were independent risk factors for inadequate bowel preparation quality (Table 4). The multivariate logistic regression analysis was run with and without preparation type (Colyte ${ }^{\circledR}$ vs MoviPrep ${ }^{\circledR}$ vs MiraLax $\left.{ }^{\circledR}\right)$ in the model. Including the type of preparation taken by the patient in the model had no clinically important or statistically significant changes in the odds ratios for the independent variables.

\section{Procedure Outcomes}

There was no significant difference in polyp detection rate or adenoma detection rate (ADR) between the 2 groups (ADR 50.2\% in the adequate preparation quality group, ADR 48.2\% in the inadequate preparation quality group; $\mathrm{p}=0.35$ ), after adjusting for BMI, tobacco and narcotics use, hypertension, diabetes and dementia. However, there was a significant impact of preparation quality on aborted procedures and follow-up intervals. No procedures $(0 \%)$ were aborted in patients with adequate preparation quality, whereas 60 colonoscopies $(6.3 \%)$ were aborted among those with inadequate preparation quality $(\mathrm{p}<0.0001)$. Further, the follow up colonoscopy interval was shortened specifically due to preparation quality in 6 patients with adequate preparation $(0.5 \%)$ as compared with 554 patients $(58.5 \%)$ with inadequate preparation quality $(\mathrm{p}<0.0001)$. Mean follow up interval was almost twice as long following an adequate preparation as compared to inadequate preparation quality: 56.7 \pm 64.1 months vs $30.2 \pm 48.2$ months ( $\mathrm{p}<0.0001)$.

\section{Discussion}

In this study, we found that obesity is an independent risk factor for inadequate bowel preparation quality in patients who receive split-dose regimens. A BMI $\geq 30 \mathrm{~kg} / \mathrm{m}^{2}$ was an independent risk factor for inadequate preparation quality. Independent of obesity, we also found that tobacco use, narcotic medications, hypertension, diabetes and dementia were associated with inadequate preparation.

Our results are consistent with previous studies that evaluated risk factors for inadequate preparation quality $(6,11-15,18)$ (Table 5$)$. Some variation is likely related to different study designs, study populations, definitions of inadequate preparation quality, and most importantly, the fact that our study is the first to strictly assess split-dose bowel preparation. An indication of constipation was found to be associated with increased likelihood of inadequate preparation quality in the study by Ness et al. (11), but not in our study, Lebwohl et al.'s (14) and Borg et al.'s (6) studies. Evaluating for most socioeconomic factors was not applicable to our study, as it was conducted at a VAMC; unmarried status and Medicaid insurance are the main socioeconomic predictors in other studies $(14,15)$. Similarly, we were not able to assess male gender as our cohort consisted largely of males. Consistent with our findings, Borg et al. (6) found that a BMI $\geq 30 \mathrm{~kg} / \mathrm{m}^{2}$ was an independent predictor of inadequate bowel preparation (OR 1.35; 95\% CI: 1.09-1.68; $\mathrm{p}=0.006$ ). In a recent Australian study, sodium picosulphate bowel preparation was prospectively assessed in 99 patients, $36 \%$ of whom were obese (19). There was no difference in good preparation quality between obese and non-obese patients ( $89 \%$ vs $90 \%$ respectively; $p>0.99$ ), and the authors concluded that a sodium picosulphate preparation is an excellent bowel preparation solution for obese patients. 
Our study has several strengths. This is the first study where all included subjects received a split-dose bowel preparation. The sample in our study is large and the study population is homogeneous. The study was conducted in the VA system, which represents the largest single provider of healthcare in the United Sates, and the second largest payor for health services after Medicare.

Our study also has limitations. This study is retrospective in design, and 261 subjects $(10.8 \%)$ were excluded due to relevant missing data. However, our final cohort included over 2000 subjects, and while we were unable to compare those excluded to the analyzed cohort, there is no reason to suspect that they would differ significantly. Our study is also a single center study from an academic VA medical center; thus, the generalizability of our results could be questioned, although they agree with the published literature in other populations. In addition, we recognize that the determination of preparation quality can vary significantly among endoscopists, particularly the definition of a fair preparation. Further, the colonoscopy reports did not routinely specify if preparation quality was ultimately documented based on the assessment preceding or following lavage and suction. While the use of the Boston bowel preparation scale (BBPS) has less interobserver variability (20), it is more cumbersome and reflects less the clinical practice compared to the Aronchick scale (17), which is used at our institution. Finally, the overall rate of inadequate preparation quality is higher in our study compared to other studies, reflecting some characteristics of our cohort, specifically, a strong male predominance and older age, and possibly due to the inclusion in the inadequate preparation group of fair preparations, a determination that is variable and subjective among endoscopists.

The effectiveness of colonoscopy depends largely on the quality of bowel preparation. In a recent study by Lebwohl et al., the adenoma miss rate due to suboptimal bowel preparation ranged between $35 \%$ and $42 \%$ (21). With an estimated $25 \%$ of patients or more not achieving adequate preparation quality for their colonoscopy $(1,5,22)$, this represents a considerable barrier to optimizing colorectal cancer screening and surveillance, and a primary reason for aborting procedures and/or repeating them at a shorter interval that guidelines recommend $(2,23)$. The importance of an adequate bowel preparation quality in obese patients is particularly important, in light of the increasing incidence of obesity in the United States and worldwide, as well as the increased prevalence of colonic adenomas amongst obese patients, which was confirmed in two recent meta-analyses $(24,25)$. Recognizing other predictors of inadequate bowel preparation is similarly important, in order to tailor the preparation based on the assessment of all potential factors that could limit the success of a standard bowel preparation. A more intensive preparation regimen could be considered in patients with a BMI $\geq 30 \mathrm{~kg} / \mathrm{m}^{2}$. Measures to improve the preparation quality include a double dose of polyethylene glycol over 2 days, the choice of an alternative product, the addition of another cathartic, longer period of dietary restriction (low residue diet and clear liquid diet), as well as patient education endeavors to optimize understanding and compliance. According to a report by the Centers for Disease Control and Prevention (CDC), the burden of obesity on healthcare spending continues to increase, accounting for $9.1 \%$ of the annual medical spending in 2008 (about $\$ 147$ billion dollars in a year) (26). Rex et al. have shown that imperfect bowel preparation increases colonoscopy costs by $12 \%$ to $22 \%$, given aborted examinations, as well as completed examinations with suboptimal preparation requiring shortened follow up (27). Improving the effectiveness of colonoscopy in obese patients could contribute to reducing healthcare cost increments, by reducing the frequency of aborted and/or repeated procedures due to inadequate preparation quality, and importantly, by decreasing the incidence of colorectal cancer in obese patients.

In conclusion, BMI is an independent risk factor for inadequate colonoscopy preparation quality among patients using split bowel preparations. Diabetes, hypertension, dementia, 
tobacco use and narcotic medications are additional risks factors that help identify patients who are also likely to require tailored preparations. A BMI $\geq 30 \mathrm{~kg} / \mathrm{m}^{2}$ should prompt consideration of a more intensive preparation regimen. Future efforts are necessary to establish and validate better preparation regimens, particularly in patients with high BMI and those with multiple predictors of unsatisfactory preparation. Improved bowel preparation results can lead to more rational and economical utilization of health care resources for prevention and early detection of colorectal cancer.

\section{Acknowledgments}

Grant Support:

This publication was supported by a Project Development Team within the ICTSI NIH/NCRR Grant Number TR000006.

\section{References}

1. Harewood GC, Sharma VK, de Garmo P. Impact of colonoscopy preparation quality on detection of suspected colonic neoplasia. Gastrointest Endosc. 2003; 58:76-9. [PubMed: 12838225]

2. Froehlich F, Wietlisbach V, Gonvers JJ, et al. Impact of colonic cleansing on quality and diagnostic yield of colonoscopy: The European panel of appropriateness of gastrointestinal endoscopy European multicenter study. Gastrointest Endosc. 2005; 61:378-84. [PubMed: 15758907]

3. Rex DK, Bond JH, Winawer S, et al. Quality in the technical performance of colonoscopy and the continuous quality improvement process for colonoscopy: Recommendations of the U.S. MultiSociety Task Force on Colorectal Cancer. Am J Gastroenterol. 2002; 97:1296-308. [PubMed: 12094842]

4. Rex DK, Petrini JL, Baron TH, et al. ASGE/ACG Taskforce on Quality in Endoscopy. Quality indicators for colonoscopy. Am J Gastroenterol. 2006; 101(4):873-85. [PubMed: 16635231]

5. Juluri R, Eckert G, Imperiale TF. Meta-analysis: randomized controlled trials of 4-L polyethylene glycol and sodium phosphate solution as bowel preparation for colonoscopy. Aliment Pharmacol Ther. 2010; 32(2):171-81. [PubMed: 20384609]

6. Borg BB, Gupta NK, Zuckerman GR, et al. Impact of Obesity on Bowel Preparation for Colonoscopy. Clin Gastroenterol Hepatol. 2009; 7:670-5. [PubMed: 19245852]

7. Rex DK, Johnson DA, Anderson JC, et al. American College of Gastroenterology guidelines for colorectal cancer screening 2009. Am J Gastroenterol. 2009; 104(3):739-50. [PubMed: 19240699]

8. Enestvedt BK, Tofani C, Laine LA, et al. 4-Liter split-dose polyethylene glycol is superior to other bowel preparations, based on systematic review and meta-analysis. Clin Gastroenterol Hepatol. 2012; 10(11):1225-31. [PubMed: 22940741]

9. Seo EH, Kim TO, Park MJ, et al. Optimal preparation-to-colonoscopy interval in split-dose PEG bowel preparation determines satisfactory bowel preparation quality: an observational prospective study. Gastrointest Endosc. 2012; 75(3):583-90. [PubMed: 22177570]

10. Kilgore TW, Abdinoor AA, Szary NM, et al. Bowel preparation with split-dose polyethylene glycol before colonoscopy: a meta-analysis of randomized controlled trials. Gastrointest Endosc. 2011; 73(6):1240-5. [PubMed: 21628016]

11. Ness RM, Manam R, Hoen H, et al. Predictors of inadequate bowel preparation for colonoscopy. Am J Gastroenterol. 2001; 96:1797-1802. [PubMed: 11419832]

12. Athreya PJ, Owen GN, Wong SW, et al. Achieving quality in colonoscopy: bowel preparation timing and colon cleanliness. ANZ J Surg. 2011; 81:261-265. [PubMed: 21418470]

13. Chung YW, Han DS, Park KH, et al. Patient factors predictive of inadequate bowel preparation using polyethylene glycol. A prospective study in Korea. J Clin Gastroenterol. 2009; 43:448-452. [PubMed: 18978506]

14. Lebwohl B, Wang T, Neuget AI. Socioeconomic and other predictors of colonoscopy preparation quality. Dig Dis Sci. 2010; 55:2014-2020. [PubMed: 20082217] 
15. Ngyyen DL, Wieland M. Risk factors predictive of poor quality preparation during average risk colonoscopy screening: the importance of health literacy. J Gastrointestin Liver Dis. 2010; 19:369-372. [PubMed: 21188326]

16. Charlson ME, Pompei P, Ales KL, et al. A new method of classifying prognostic comorbidity in longitudinal studies: development and validation. J Chronic Dis. 1987; 40:373-83. [PubMed: 3558716]

17. Aronchick CA, Lipshutz WH, Wright SH, et al. Validation of an instrument to assess colon cleansing. Am J Gastroenterol. 1999; 94:2667. abstract.

18. Hassan C, Fuccio L, Bruno M, et al. A predictive model identifies patients most likely to have inadequate bowel preparation for colonoscopy. Clin Gastroenterol Hepatol. 2012; 10(5):501-6. [PubMed: 22239959]

19. Fok KC, Turner IB, Teoh WC, et al. Obesity does not affect sodium picosulphate bowel preparation. Intern Med J. 2012; 42(12):1324-9. [PubMed: 22757662]

20. Lai EJ, Calderwood AH, Doros G, et al. The Boston bowel preparation scale: a valid and reliable instrument for colonoscopy-oriented research. Gastrointest Endosc. 2009; 69:620-5. [PubMed: 19136102]

21. Lebwohl B, Kastrinos F, Glick M, et al. The impact of suboptimal bowel preparation on adenoma miss rates and the factors associated with early repeat colonoscopy. Gastrointest Endosc. 2011; 73(6):1207-14. [PubMed: 21481857]

22. Kazarian ES, Carreira FS, Toribara NW, et al. Colonoscopy completion in a large safety net health care system. Clin Gastroenterol Hepatol. 2008; 6(4):438-42. [PubMed: 18304886]

23. Rex DK. Maximizing Detection of Adenomas and Cancers during Colonoscopy. Am J Gastroenterol. 2006; 101:2866-2877. [PubMed: 17227527]

24. Okabayashi K, Ashrafian H, Hasegawa H, et al. Body mass index category as a risk factor for colorectal adenomas: a systematic review and meta-analysis. Am J Gastroenterol. 2012; 107(8): 1175-85. [PubMed: 22733302]

25. Ben Q, An W, Jiang Y, et al. Body mass index increases risk for colorectal adenomas based on meta-analysis. Gastroenterology. 2012; 142(4):762-72. [PubMed: 22245665]

26. Finkelstein EA, Trogdon JG, Cohen JW, et al. Annual medical spending attributable to obesity: payer- and service-specific estimates. Health Aff (Millwood). 2009; 28(5):w822-31. [PubMed: 19635784]

27. Rex DK, Imperiale TF, Latinovich DR, et al. Impact of bowel preparation on efficiency and cost of colonoscopy. Am J Gastroenterol. 2002; 97(7):1696-700. [PubMed: 12135020]

\section{Abbreviations}

$\begin{array}{ll}\text { ADR } & \text { Adenoma Detection Rate } \\ \text { BMI } & \text { Body-Mass Index } \\ \text { CPRS } & \text { Computerized Patient Record System } \\ \text { CRC } & \text { Colorectal Cancer } \\ \text { VAMC } & \text { Veterans Affairs Medical Center }\end{array}$

Clin Gastroenterol Hepatol. Author manuscript; available in PMC 2014 November 01. 
Table 1

Characteristics of Patients with Adequate and Inadequate Preparation Quality.

\begin{tabular}{|c|c|c|c|c|}
\hline & All Subjects (n=2163) & $\begin{array}{l}\text { Adequate Preparation Quality } \\
(\mathbf{n = 1 2 0 7 )}\end{array}$ & $\begin{array}{l}\text { Inadequate Preparation } \\
\text { Quality }(n=956)\end{array}$ & p-value \\
\hline Male gender, $\mathrm{n}(\%)$ & $2008(93.8 \%)$ & $1110(93.0 \%)$ & $898(94.9 \%)$ & 0.0701 \\
\hline Age (years), mean \pm SD & $60.6 \pm 10.5$ & $60.2 \pm 10.8$ & $61.1 \pm 10.0$ & 0.0430 \\
\hline Race, n (\%) & & & & 0.3045 \\
\hline White & $1587(82.5 \%)$ & $876(81.7 \%)$ & $711(83.5 \%)$ & \\
\hline Non-White & $336(17.5 \%)$ & $196(18.3 \%)$ & $140(16.5 \%)$ & \\
\hline Hispanic, n (\%) & $12(0.7 \%)$ & $6(0.6 \%)$ & $6(0.75 \%)$ & 0.7749 \\
\hline BMI, n (\%) & & & & $<0.0001$ \\
\hline Normal & $381(17.6 \%)$ & $233(19.3 \%)$ & $148(15.5 \%)$ & \\
\hline Overweight & $774(35.8 \%)$ & $473(39.2 \%)$ & $301(31.5 \%)$ & \\
\hline Obese & $1008(46.6 \%)$ & $501(41.5 \%)$ & $507(53.0 \%)$ & \\
\hline $\mathrm{BMI}\left(\mathrm{Kg} / \mathrm{m}^{2}\right)$, mean $\pm \mathrm{SD}$ & $30.4 \pm 6.2$ & $29.8 \pm 5.9$ & $31.2 \pm 6.5$ & $<0.0001$ \\
\hline Tobacco Use, n (\%) & $848(39.4 \%)$ & $447(37.2 \%)$ & $401(42.2 \%)$ & 0.0209 \\
\hline Alcohol Use, n (\%) & & & & 0.0297 \\
\hline Excessive & $191(8.9 \%)$ & $105(8.8 \%)$ & $86(9.1 \%)$ & \\
\hline Social & $704(32.9 \%)$ & $422(35.3 \%)$ & $282(29.9 \%)$ & \\
\hline No use & $1244(58.2 \%)$ & $669(55.9 \%)$ & $575(61.0 \%)$ & \\
\hline Family history of CRC, n (\%) & $205(9.6 \%)$ & $119(9.9 \%)$ & $87(9.2 \%)$ & 0.6057 \\
\hline Colonoscopy Indication, $\mathrm{n}(\%)$ & & & & 0.0209 \\
\hline Screening & $746(34.6 \%)$ & $446(37.0 \%)$ & $300(31.4 \%)$ & \\
\hline Surveillance & $737(34.1 \%)$ & $401(33.3 \%)$ & $336(35.2 \%)$ & \\
\hline Diagnostic & $675(31.3 \%)$ & $357(29.7 \%)$ & $318(33.4 \%)$ & \\
\hline *Constipation & $22(1.0 \%)$ & $11(0.9 \%)$ & $11(1.2 \%)$ & \\
\hline Preparation Type, n (\%) & & & & 0.5976 \\
\hline Colyte $^{\circledR}$ & $1953(91.1 \%)$ & $1098(91.5 \%)$ & $855(90.6 \%)$ & \\
\hline MoviPrep ${ }^{\circledR}$ & $45(2.1 \%)$ & $26(2.2 \%)$ & $19(2.0 \%)$ & \\
\hline MiraLax $^{\circledR}$ & $146(6.8 \%)$ & $76(6.3 \%)$ & $70(7.4 \%)$ & \\
\hline
\end{tabular}

SD, Standard Deviation; BMI, Body Mass Index; CRC, Colorectal Cancer 


\section{Table 2}

Comorbidities and Medications Use in Patients with Adequate and Inadequate Preparation Quality.

\begin{tabular}{|c|c|c|c|c|}
\hline & All Subjects $(n=2163)$ & $\begin{array}{l}\text { Adequate Preparation } \\
\text { Quality (n=1207) }\end{array}$ & $\begin{array}{l}\text { Inadequate Preparation } \\
\text { Quality }(n=956)\end{array}$ & p-value \\
\hline \multicolumn{5}{|l|}{ Comorbidities } \\
\hline Coronary Artery Disease, n (\%) & $428(20.3 \%)$ & $209(17.8 \%)$ & $219(23.5 \%)$ & 0.0015 \\
\hline Congestive Heart Failure, n (\%) & $124(5.9 \%)$ & $58(5.0 \%)$ & $66(7.1 \%)$ & 0.0403 \\
\hline Diabetes, n (\%) & $638(30.2 \%)$ & $307(26.0 \%)$ & $331(35.5 \%)$ & $<0.0001$ \\
\hline Hypertension, n (\%) & $1403(65.5 \%)$ & $737(61.7 \%)$ & $666(70.3 \%)$ & $<0.0001$ \\
\hline Dementia, n (\%) & $27(1.3 \%)$ & $9(0.8 \%)$ & $18(1.9 \%)$ & 0.0198 \\
\hline Stroke, n $(\%)$ & $100(4.8 \%)$ & $48(4.1 \%)$ & $52(5.6 \%)$ & 0.1217 \\
\hline Liver Cirrhosis, n (\%) & $53(2.5 \%)$ & $24(2.1 \%)$ & $29(3.1 \%)$ & 0.1247 \\
\hline Number of comorbidities, mean \pm SD & $1.0 \pm 1.1$ & $0.9 \pm 1.1$ & $1.2 \pm 1.2$ & $<0.0001$ \\
\hline Charlson index, mean $\pm \mathrm{SD}$ & $1.3 \pm 1.5$ & $1.1 \pm 1.4$ & $1.5 \pm 1.6$ & $<0.0001$ \\
\hline \multicolumn{5}{|l|}{ Pertinent Medications } \\
\hline Narcotics, n (\%) & $556(25.7 \%)$ & $285(23.6 \%)$ & $271(28.3 \%)$ & 0.0132 \\
\hline Calcium Channel Blockers, n (\%) & $339(15.7 \%)$ & $170(14.1 \%)$ & $169(17.7 \%)$ & 0.0237 \\
\hline Anticholinergics, n (\%) & $428(19.8 \%)$ & $224(18.6 \%)$ & $204(21.3 \%)$ & 0.1151 \\
\hline Iron Supplements, $\mathrm{n}(\%)$ & $121(5.6 \%)$ & $64(5.3 \%)$ & $57(6.0 \%)$ & 0.5112 \\
\hline Anticonvulsants, n (\%) & $69(3.2 \%)$ & $31(2.6 \%)$ & $38(4.0 \%)$ & 0.0839 \\
\hline
\end{tabular}

SD, Standard Deviation 
Table 3

Univariate Logistic Regression of Association of BMI and Inadequate Bowel Preparation Quality.

\begin{tabular}{|l|l|l|l|}
\hline & OR & 95\% CI & p-value \\
\hline BMI $\left(\mathrm{Kg} / \mathrm{m}^{2}\right)$ - continuous & 1.04 & $1.02-1.05$ & $<0.0001$ \\
\hline Overweight vs Normal BMI & 1.00 & $0.78-1.28$ & 0.9887 \\
\hline Obese vs Normal BMI & 1.59 & $1.25-2.03$ & 0.0001 \\
\hline Obese vs Overweight & 1.59 & $1.32-1.92$ & $<0.0001$ \\
\hline
\end{tabular}

OR, Odds Ratio; CI, Confidence Interval 
Table 4

Independent Risk Factors for Inadequate Bowel Preparation Quality*.

\begin{tabular}{|l|l|l|l|}
\hline & OR & 95\% CI & p-value \\
\hline BMI $\geq 30 \mathrm{Kg} / \mathrm{m}^{2}$ & 1.46 & $1.21-1.75$ & $<0.0001$ \\
\hline Tobacco use & 1.28 & $1.07-1.54$ & 0.0084 \\
\hline Narcotics use & 1.28 & $1.04-1.57$ & 0.0179 \\
\hline Hypertension & 1.30 & $1.07-1.57$ & 0.0085 \\
\hline Diabetes & 1.38 & $1.12-1.69$ & 0.0021 \\
\hline Dementia & 3.02 & $1.22-7.49$ & 0.0169 \\
\hline
\end{tabular}

OR, Odds Ratio; CI, Confidence Interval

Results from final multivariable logistic regression model. 


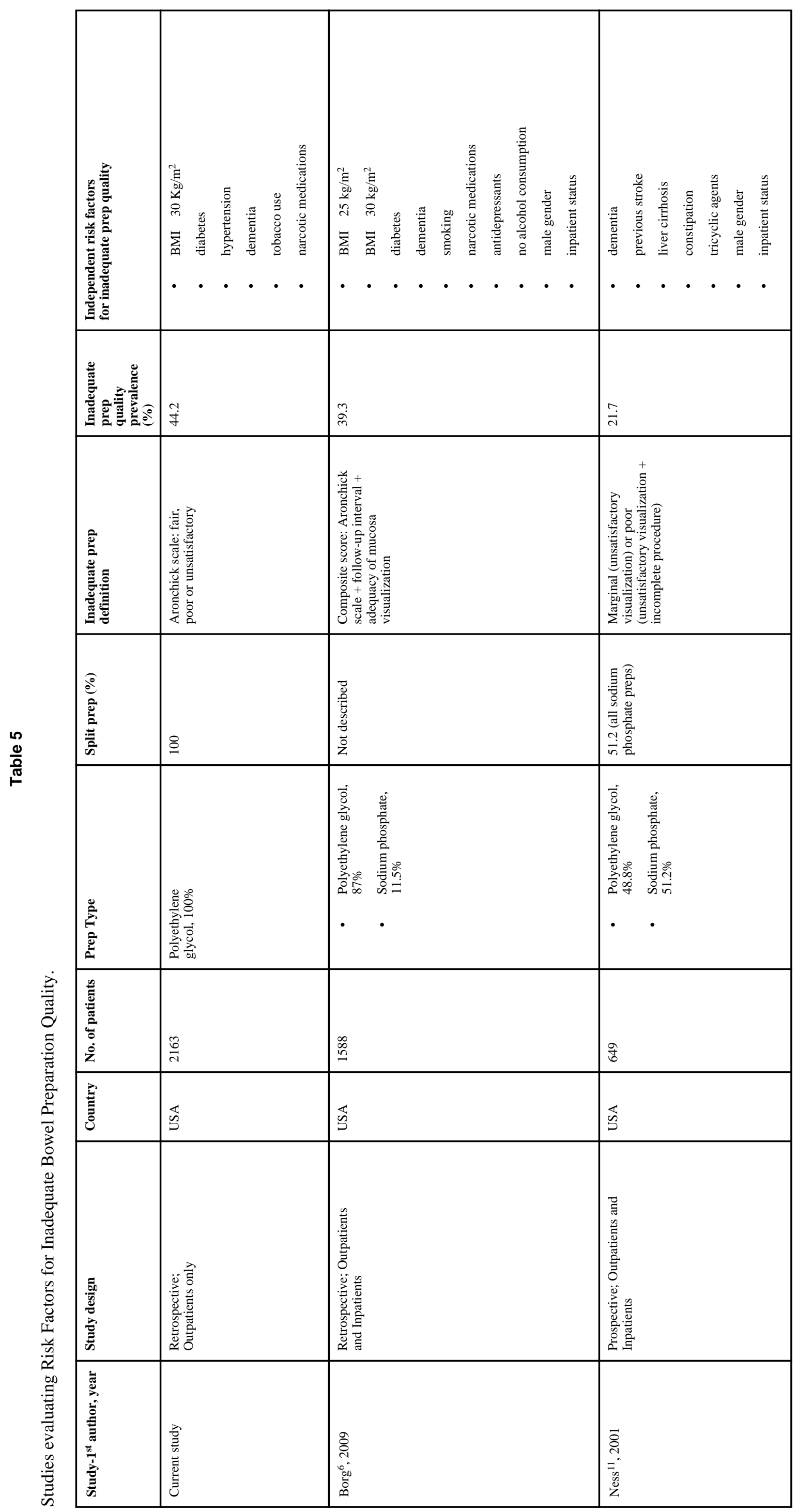

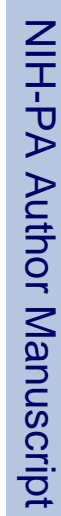

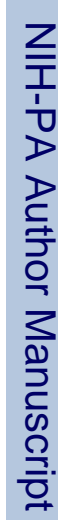

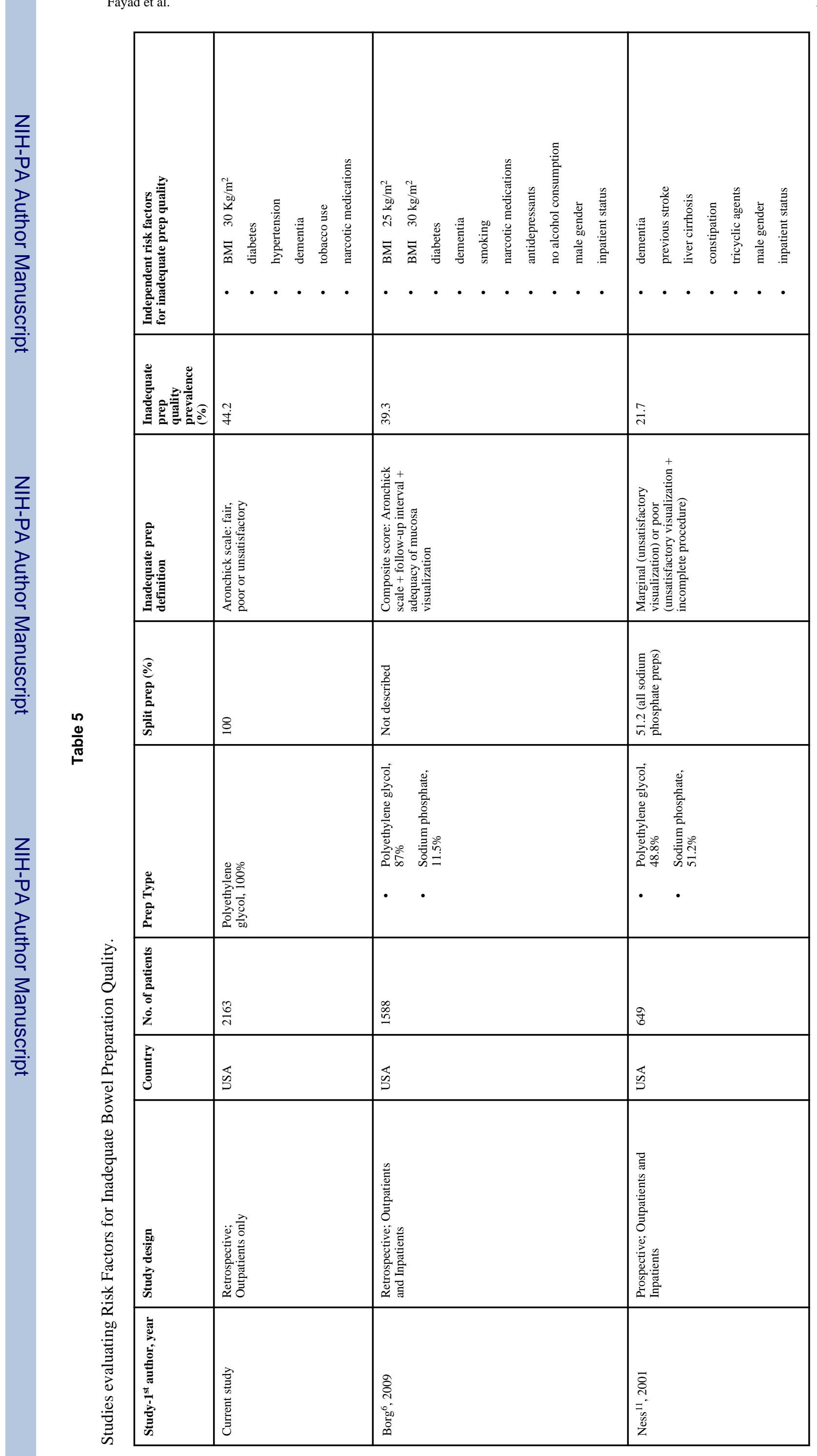




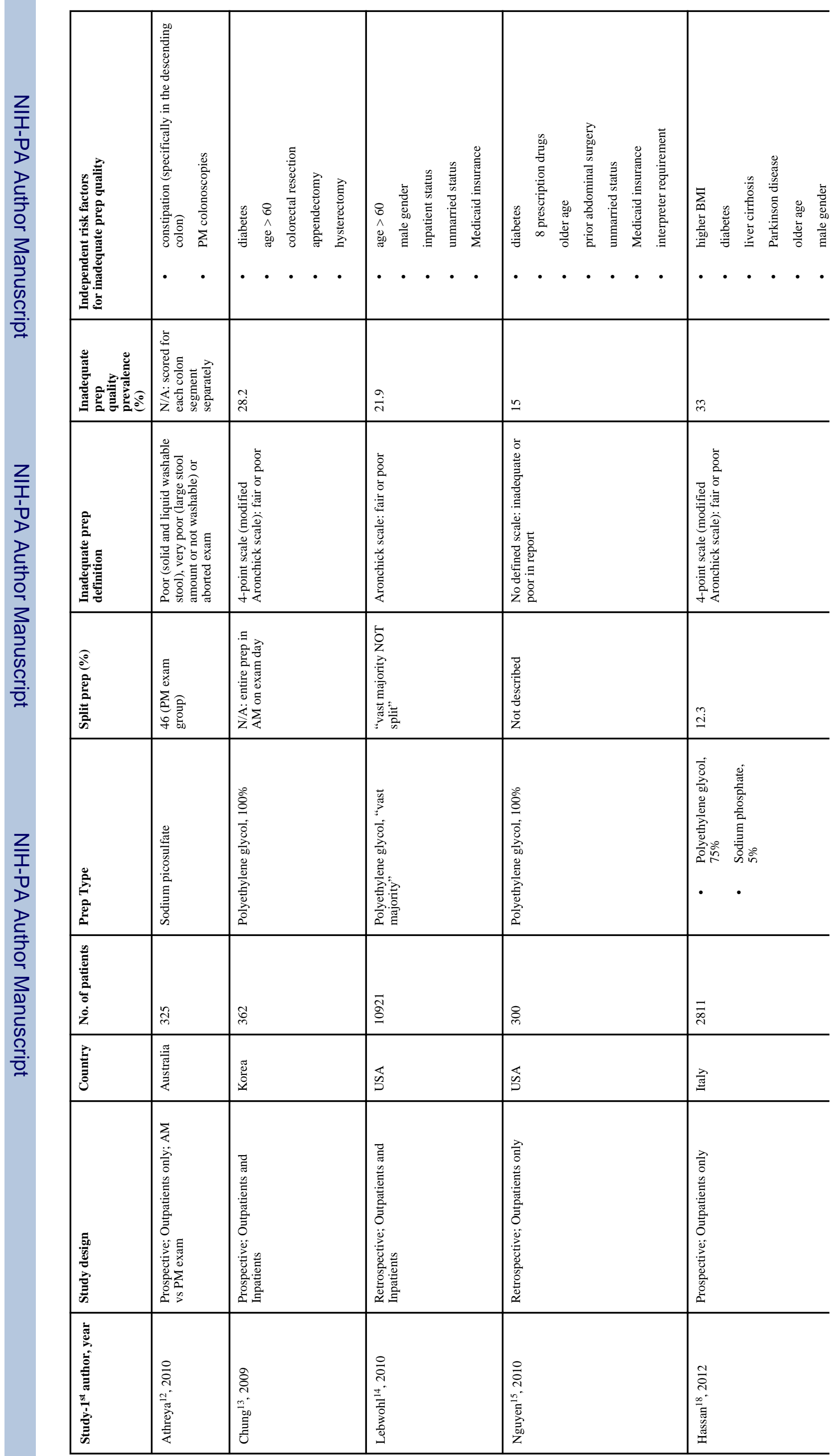




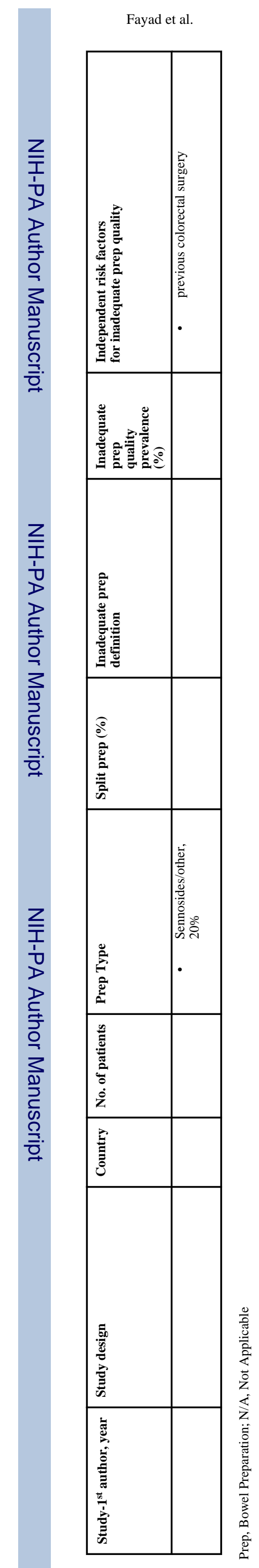

